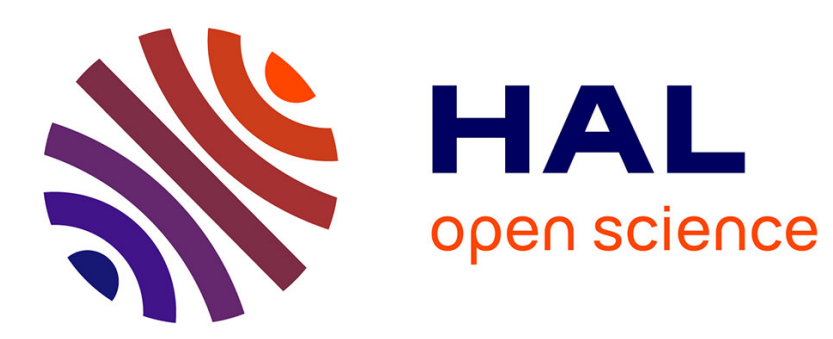

\title{
SURFACE MECHANISMS IN THE UVCVD OF SiO2 FILMS
}

\author{
C. Licoppe, C. Meriadec, J. Flicstein, Y. Nissim, E. Petit, J. Moison
}

\section{To cite this version:}

C. Licoppe, C. Meriadec, J. Flicstein, Y. Nissim, E. Petit, et al.. SURFACE MECHANISMS IN THE UVCVD OF SiO2 FILMS. Journal de Physique IV Proceedings, 1991, 02 (C2), pp.C2-357-C2-364. 10.1051/jp4:1991243 . jpa-00249833

\section{HAL Id: jpa-00249833 https://hal.science/jpa-00249833}

Submitted on 1 Jan 1991

HAL is a multi-disciplinary open access archive for the deposit and dissemination of scientific research documents, whether they are published or not. The documents may come from teaching and research institutions in France or abroad, or from public or private research centers.
L'archive ouverte pluridisciplinaire HAL, est destinée au dépôt et à la diffusion de documents scientifiques de niveau recherche, publiés ou non, émanant des établissements d'enseignement et de recherche français ou étrangers, des laboratoires publics ou privés. 
Colloque C2, suppl. au Journal de Physique II, Vol. 1, septembre 1991

\title{
SURFACE MECHANISMS IN THE UVCVD OF $\mathrm{SiO}_{2}$ FILMS
}

\author{
C. LICOPPE, C. MERIADEC, J. FLICSTEIN, Y.I. NISSIM, E. PETIT \\ and J.M. MOISON
}

Groupement CNET/CNRS, Laboratoire de Bagneux, Centre NationaI d'Études des Télécommunications. 196 avenue Henri Ravera, F-92220 Bagneux, France

\begin{abstract}
Surface-sensitive multiple internal reflection absorption infrared spectroscopy has been applied to the study of the growth of $\mathrm{SiO}_{2}$ films under far ultraviolet illumination. Spectra provide evidence for a previously unreported $\mathrm{Si}-\mathrm{H}$ absorption peak occurring at $2208 \mathrm{~cm}^{-1}$. It is shown that this line characterizes the molecular structure of the photochemisorption site of silane and that this phenomenon occurs on sites including hydroxyl groups which are also produced in a photochemical gas-solid process. In the first step of silane photochemisorption, photoexcitation occurs on the surface while in the oxidization step, photoexcitation of oxygen molecules is an active process in the gas phase.
\end{abstract}

\section{1.-Introduction}

Photochemical deposition of dielectric materials such as $\mathrm{SiO}_{2}$ is increasingly employed as a low-temperature process for device fabrication/1/. Photodeposition processes are challenging to the physicist, because it is difficult to obtain convincing evidence for the nature of the surface physico-chemistry involved in such processes. The purpose of this paper is to provide the first evidence of this kind in the case of the photodeposition of $\mathrm{SiO}_{2}$ thin films from gaseous silane/oxygen mixture under irradiation by low pressure mercury lamps with lines at $185 \mathrm{~nm}$ and $254 \mathrm{~nm}$. Its obtention was made possible by the construction of a surface-sensitive infrared vibrational absorption experiment which was associated to a UVCVD system, yielding in situ surface absorption optical measurements.

\section{2.- Experimental}

The experimental apparatus is composed of a rapid thermal chemical vapour deposition (CVD) vessel/2/ equipped with low pressure mercury lamps providing UV lines at 183 and 254 $\mathrm{nm}$ and coupled to a modified Nicolet $740 S X$ spectrometer through $\mathrm{ZnSe}$ windows. CVD growth occured on both sides of a semiconductor prisın made of iron-doped semi-insulating InP. . It was cut into a rectangular shape, $50 \mathrm{~mm}$ long, $5 \mathrm{~mm}$ wide and $1 \mathrm{~mm}$ thick with both edges bevelled at $45^{\circ}$. The experimental geometry allows for about 40 total internal reflections on each face. The sensitivity of the system is $\Delta R / R=5.10^{-5}$ at $2000 \mathrm{~cm}^{-1}$ with 1000 scans of the interferometer, so that $1 / 50$ th of a monolayer of $\mathrm{SiO}_{2}$ could be detected on InP. The indium phosphide (100) internal reflection element is transparent above $1000 \mathrm{~cm}^{-1}$. Data are taken in unpolarized light with a resolution of $4 \mathrm{~cm}^{-1}$. X-Ray photoemisson spectroscopy experiments were performed in a UHV chamber with a base pressure of $10^{-11}$ Torr. 

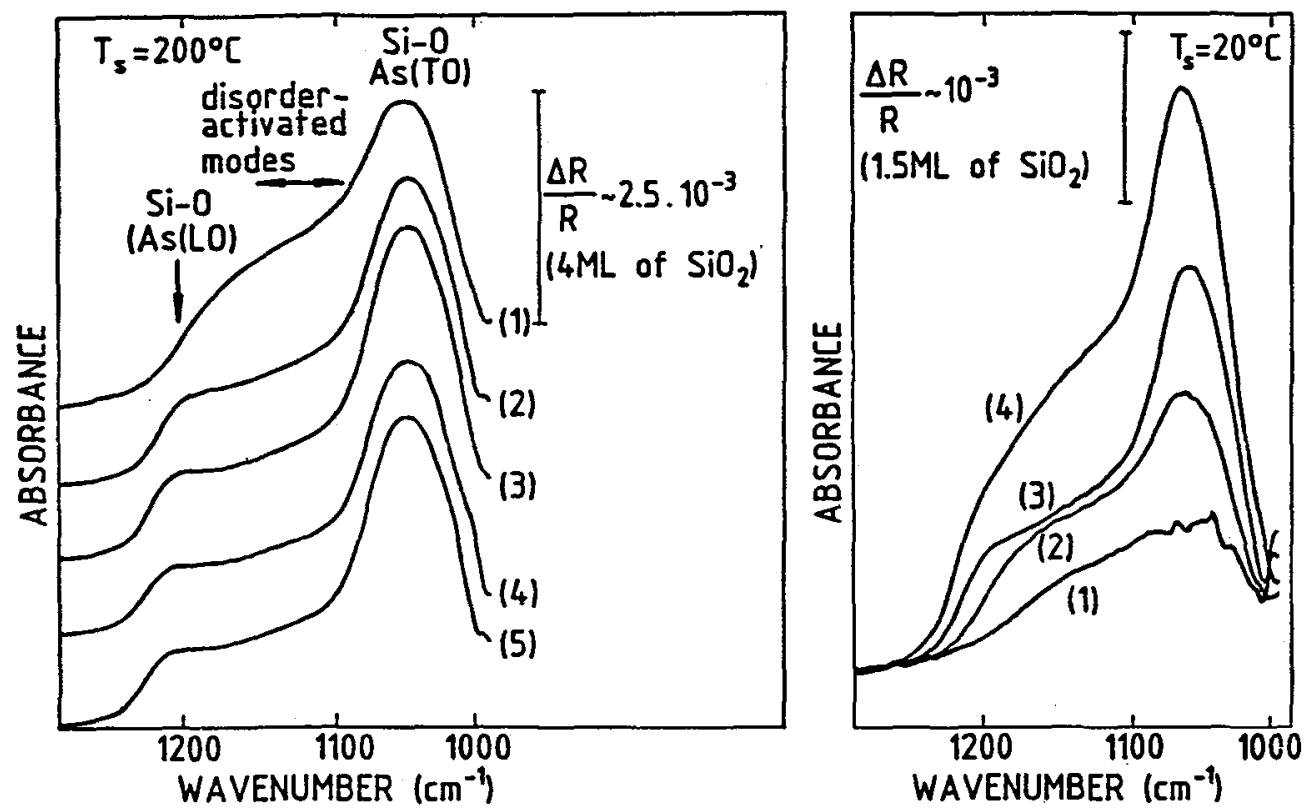

Figure 1

Multiple infrared reflection-absorption spectra in the Si-O stretching region for consecutive UVCVD growth cycles of $\mathrm{SiO}_{2}$ performed at $200^{\circ} \mathrm{C}$ (Figure 1a) and room temperature (Figure 1b). Spectra are indexed according to the sequence of growth cycles. Spectrum $n$ shows the difference in the absorbance spectrum between the sample after $n$ growth cycles and the sample after $n-1$, thus figuring the specific contribution of the $n$th growth cycle to the infrared absorbance. A positive absorption peak means addition of Si-O bonds during the cycle.

Contrary to the high temperature case, films grown at room temperature exhibited porosity and surface roughness. This is seen from the high level of absorption in the $1100-1200 \mathrm{~cm}^{-1}$ region, which has been assigned to disorder-activated modes $/ 4 /$, and which systematically correlated in our experiments with $\mathrm{i}$ ) a high density of $\mathrm{Si}-\mathrm{H}$ bonds which locally terminates the amorphous network ii) a rough surface morphology in scanning electron microscopy iii) electrical leakage in the case of thicker layers. Therefore room temperature photodeposited silica layers have a high degree of porosity. Since this means a higher surface-to-volume ratio than in high temperature photodeposited films where deposition rates are constant, the fact that the deposition rate increases with the amount of photodeposited silica suggests the photodeposition rate to be dominated by surface mechanisms. 


\section{4.- Infrared absorption in the Si-H region.}

Figure 2 shows the differential infrared spectra observed after 5 runs at $200^{\circ} \mathrm{C}$ in the region of the $\mathrm{Si}-\mathrm{H}$ stretching resonances, with different substrate temperatures. Two distinct absorption peaks can be observed at 2260 and $2208 \mathrm{~cm}^{-1}$ with a full width at medium height (FWMH) of $50 \mathrm{~cm}^{-1}$. The peak at $2260 \mathrm{~cm}^{-1}$ is a regular feature of hydrogen-containing $\mathrm{SiO}_{2}$ films : it is assigned to the hydrogen stretching of a $\mathrm{O}_{3} \mathrm{Si}-\mathrm{H}$ unit and it is directly related to the $\mathrm{Si}-\mathrm{H}$ stretch at $2000 \mathrm{~cm}^{-1}$ currently observed in aSi:H, shifted to higher energies because of the stronger electronegativities of the backbonding oxygen atoms $/ 5 /$. The signal is highest for the first growth cycle and it shows a subsequent evolution towards a stationary regime where a constant relative amount of these defects is incorporated into the film; this regime persists for thicker films. This is consistent with the classical observation of such defects in the bulk of deposited $\mathrm{SiO}_{2}$ films.
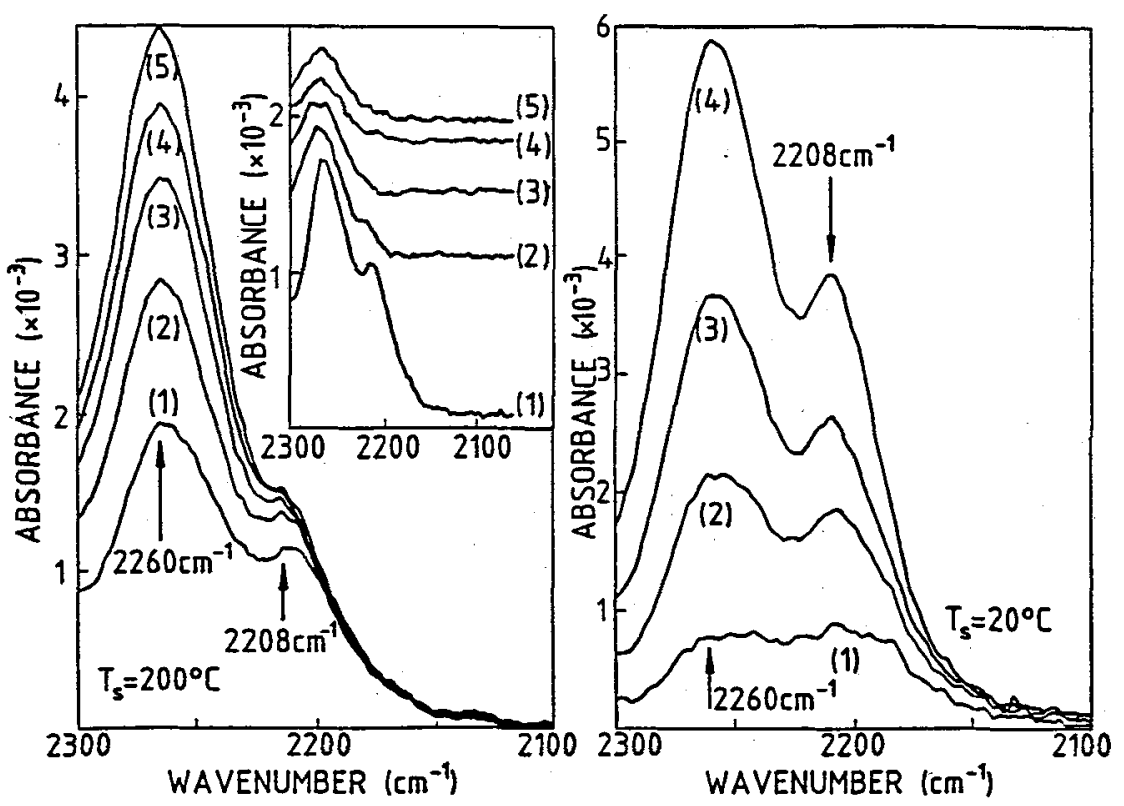

Figure 2

Multiple infrared reflection-absorption spectra in the Si-H stretching region for consecutive UVCVD growth cycles of $\mathrm{SiO}_{2}$ performed at $200^{\circ} \mathrm{C}$ (Figure 2a) and room temperature (Figure $2 b)$. Spectra are indexed according to the sequence of growth cycles.

The other line observable in the Si-H stretching region is located at $2208 \mathrm{~cm}^{-1}$. It has not been observed before, and it will be shown to be produced by a photo-induced chemisorption site of 
silane. For growth runs performed at $200^{\circ} \mathrm{C}$ (figure 1a), this specific feature disappears after the first run in the differential spectra of the new material added by following growth runs. Possible reasons are, either it is related to an interface bonding configuration which additional $\mathrm{SiO}_{2}$ covers without removing, or it is related to a surface state of the growing overlayer. The hypothesis of a buried interfacial defect is inconsistent with the room-temperature data, where it keeps being produced over thicker films. On the other hand, the surface site hypothesis fits the observations that porosity and surface roughness lead to an increase in the surface-to-volume ratio as the deposition proceeds with a regular addition of active surface sites, and therefore to the persistence of the corresponding surface line at $2208 \mathrm{~cm}^{-1}$. Moreover, this vibrational surface peak was not observed in the layers grown at $200^{\circ} \mathrm{C}$ by a purely thermal process with longer exposure times. In the case of single-gas treatments, it could not be observed in anycase whatsoever, unless the UV lamp was turned on. This line is therefore associated to a surface site whose production is directly related to UV irradiation.

Thus interpreted, the behaviour of this absorption line at $2208 \mathrm{~cm}^{-1}$ enable us to refine the remarks about the porosity of the films made in the previous sections. Since it has been assigned to a surface site, its intensity can be taken as an estimate of the surface extension. At $200^{\circ} \mathrm{C}$, it keeps constant, providing evidence for a stationary interface morphology. The observation of a constant deposition rate puts more weight on the idea of a surface-controlled photodeposition process. At $20^{\circ} \mathrm{C}$, it is readily seen that the intensity of this line increases with film thickness, hence the number of surface sites increases with the deposition rate, maintaining the overall consistency of our description of the photodeposition process.

\section{5.- The origin of the Si-H absorption line at $2208 \mathrm{~cm}-1$}

It is related to the reaction of silane with the surface, as shown by the experiments described in figure 3. A film grown at room temperature is exposed twice to oxygen and UV. The Si-H bonds vibrating at $2208 \mathrm{~cm}^{-1}$ are about five times more reactive to photo-excited oxygen than those at $2260 \mathrm{~cm}^{-1}$, and they disappear preferentially during oxygen exposures as the curve a and $b$ of figure 2 show. After these treatments which remove three-quarters of the $2208 \mathrm{~cm}^{-1}$ band, the surface is exposed to silane and UV light, and an increase of the peak at $2208 \mathrm{~cm}^{-1}$ is observed (curve $c$ ). This sequence involving oxygen and then silane exposures is the only one that leads to a net increase in the peak at $2208 \mathrm{~cm}^{-1}$. By contrast with the $2260 \mathrm{~cm}^{-1} \mathrm{Si}-\mathrm{H}$ line, which can be produced by heating the film in a neutral ambient and thus is also due to intra-surface reactions, the $2208 \mathrm{~cm}^{-1}$ line therefore characterizes a photochemisorption site of silane, resulting only from gas-surface processes. We can estimate the number of such sites, for instance on the surface of the film grown at $200^{\circ} \mathrm{C}$ in figure 1 a, by using previous calibrations of infrared data $/ 6 /$ : 
if the molecular unit giving rise to the $\mathrm{Si}-\mathrm{H}$ line involves $\mathrm{n} \mathrm{Si}-\mathrm{H}$ bonds, this number is $4 / 5 \mathrm{n}$ monolayers. Since $\mathrm{n}$ can be 1,2 or 3 , it is clear that an important fraction of the growth surface is covered by photochemisorbed silane.

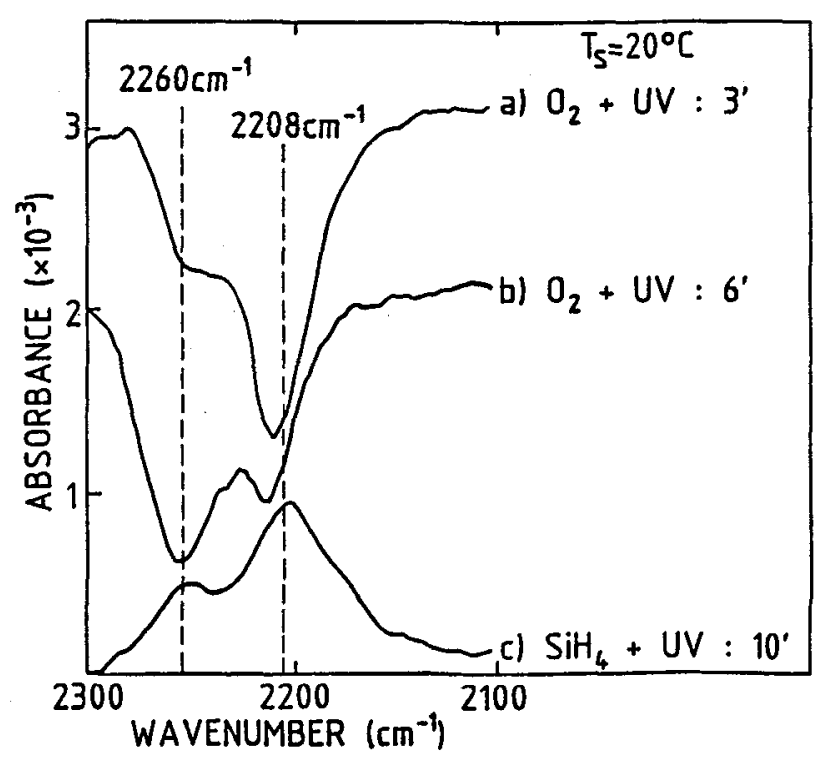

Figure 3

Modifications in the $\mathrm{Si}-\mathrm{H}$ region of the absorbance spectrum of an as-grown ultrathin silica film due to specific gaseous treatments. These were all performed at a pressure of 2 Torr and at room temperature. As in figure 1, positive absorbance peaks mean addition of Si-H bonds while negative peaks indicate removal of such bonds during the treatment. In the sequence of treatments described here, the sample was exposed to oxygen and UV irradiation for 3 minutes (curve a) and then again 6 minutes (curve b), and to silane and UV irradiation for 10 minutes (curve c), figuring at last an addition of $\mathrm{Si}-\mathrm{H}$ bonds.

\section{6.- Adsorbed water in the surface reactions.}

To understand what types of sites on the surface are active for photochemisorption, a convenient starting point is the observation that photo-induced chemisorption of silane could only be observed after exposures of the films to photo-excited oxygen at room-temperature. Gas-phase photochemistry studies/7/ have demonstrated the high reactivity of $\mathrm{Si}-\mathrm{H}$ features to photoexcited oxygen and its capacity to break $\mathrm{Si}-\mathrm{H}$ bonds and produce hydroxyl groups. To check 
on the importance of such groups, a freshly grown film was exposed under UV irradiation to oxygen and then to silane. The behaviour of the $\mathrm{Si}-\mathrm{H}$ features in the spectrum was similar to that reported in figure 3, and that of the $\mathrm{O}-\mathrm{H}$ band is reported in figure 4a. Curve a shows an increase in the signal around $3350 \mathrm{~cm}^{-1}$, which is usually attributed to water. The overall behaviour in the gas-surface photochemistry thus agrees with the conclusions of gas-phase studies, with conversion of some $\mathrm{Si}-\mathrm{H}$ features into $\mathrm{OH}$-containing groups. Curve $b$ in figure 4a shows that the subsequent silane exposure consumes $\mathrm{O}-\mathrm{H}$ bonds. As shown in a parallel experiment, this consumption cannot be accounted by UV irradiation alone, which acts much more slowly on the O-H bonds.

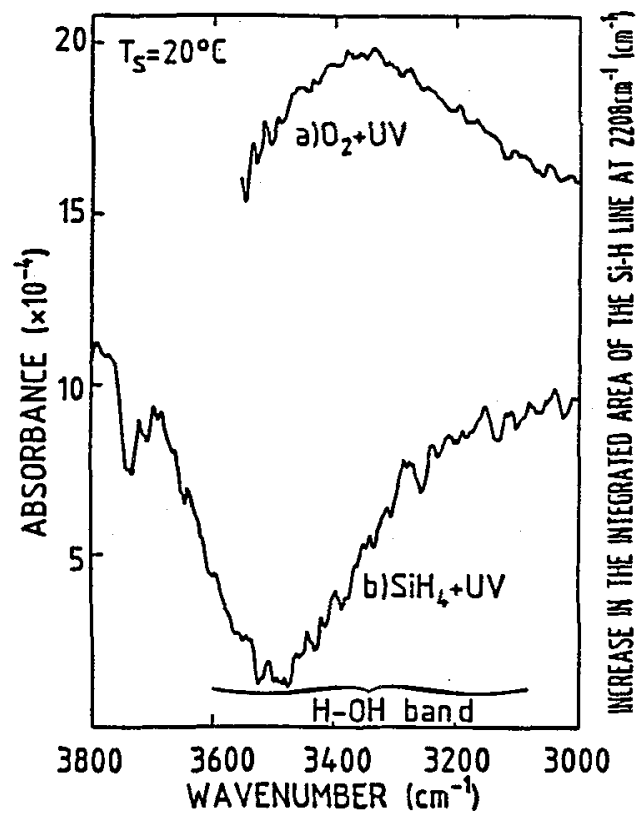

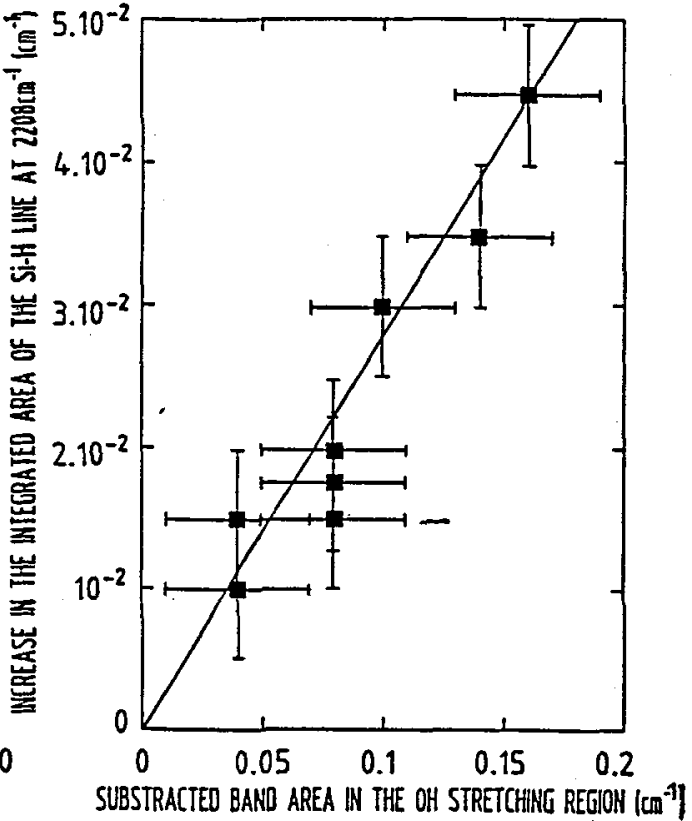

Figure 4

(a) Differential spectra in the $\mathrm{OH}$ region of an annealed $\mathrm{SiO}_{2}$ deposit following $\mathrm{O}_{2}+\mathrm{UV}$ exposure and then $\mathrm{SiH} 4+\mathrm{UV}$ exposure.

(b) Integrated absorbance of the $\mathrm{OH}$ groups versus integrated absorbance of the Si-H 2208 $\mathrm{cm}^{-1}$ line for increasing $\mathrm{SiH}_{4}+\mathrm{UV}$ exposures of this annealed $\mathrm{SiO}_{2}$ deposit.

By carefully heating the film before performing the oxygen and silane exposure sequence so as to anneal away bulk $\mathrm{O}-\mathrm{H}$ bonds, it is possible to visualize the surface creation of hydroxyl and their consumption in the silane photochemisorption process. The integrated absorbance of the Si-H signal at $2208 \mathrm{~cm}^{-1}$ added during the silane photo-exposure is plotted in figure $4 \mathrm{~b}$ as a function of the integrated absorbance of the $\mathrm{O}-\mathrm{H}$ bonds which disappear during the same 
exposures. As expected, a linear relationship is obtained. Taking a standard attenuation coefficient in silica glasses of $77 \mathrm{~mol} . \mathrm{cm} / 1 / 8 /, 0.55 \mathrm{ml}$ of surface $\mathrm{O}-\mathrm{H}$ bonds are consumed in order to produce $4 / 5 \mathrm{n} \mathrm{ml}$ of photochemisorbed silane. In view of the uncertainties of the calibration data on the $\mathrm{O}-\mathrm{H}$ bands, this is quite consistent with the assumption that silane photochemisorbs on $\mathrm{O}-\mathrm{H}$ related sites, breaking one or two hydroxyl bonds at a time, according to the value of n.

\section{7.- Conclusion}

The UV surface photochemistry involved in silica photodeposition can be then read as a two-step photochemisorption process. Photo-activated oxygen produced by UV irradiation breaks Si-H bonds and produces Si-O bonds and hydroxyl groups. Silane, which does not absorb UV light at $185 \mathrm{~nm}$ in the gas phase /9/, photochemisorbs on water-related species, which does absorb UV light in this UV range /10/, producing Si-O and Si-H bonds. Temperature competes with this photochemical growth channel because heating is the most efficient process to remove $\mathrm{O}-\mathrm{H}$ bonds. We have also observed temperature to induce alternative growth channels, for instance allowing silane incorporation without UV irradiation at $200^{\circ} \mathrm{C}$, a reaction that leads to the production of $\mathrm{Si}-\mathrm{O}$ bonds and $\mathrm{O}_{3} \mathrm{Si}-\mathrm{H}$ bonds. Hence, the $\mathrm{UV}$ reaction path predominates at low temperatures, while its influence vanishes at higher temperatures, as was previously observed to occur above $200^{\circ} \mathrm{C}$. This accounts for the porosity and surface roughness observed in films grown at room temperature, because the discrete and random character of chemisorption processes favour the development of geometrical disorder at the surface during growth. 


\section{References}

/1/ H.Stafast Appl.Phys.A 4593 (1988) and references within.

12/ Y.I.Nissim, J.M.Moison, F.Houzay, F.Lebland, C.Licoppe and M.Bensoussan Appl.Surf.Science 46175 (1990)

13/ F.J.Himpsel, F.R.Mac Feely, A.Taleb-Ibrahimi, J.A.Yarmoff and G.Hollinger Phys.Rev.B38 6064 (1988) ; F.R.Mac Feely, E.Cartier, J.A.Yarmoff and S.A.Joyce Phys.Rev.B42 5191 (1990).

14/ C.T.Kirk Phys.Rev.B38 1255 (1988) ; P.Lange J.Appl.Phys.66 201 (1989)

15/ G.Lucovsky Sol.St.Comm.29 571 (1979).

/6/ K.H.Beckmann and N.J.Harrick J.Electrochem.Soc. 118614 (1971); W.R.Knolle, H.R.Maxwell and R.E.Benenson J.Appl.Phys.51 4385 (1980)

7/ B.S.Agrawalla and D.W.Setser J.Chem.Phys. 865421 (1987) ; C.R.Park, G.D.White and J.R.Wiesenfeld J.Phys.Chem.92 152 (1988) ; S.Koda, S.Tsuchiya, T.Suzuki, C.Yamada and E.Hirota Chem.Phys.Lett. 16135 (1989)

/8/ G.W.Stephenson and K.H.Jack Trans.Brit.Ceram.Soc. 59397 (1960) ; A.J.Moulson and J.P.Roberts Trans.Faraday.Soc. 571208 (1961).

19/ Y.Harada, J.N.Murell and H.H.Sheena Chem.Phys.Lett.1 595 (1968) ; R.Roberge, C.Sandorfy, J.I.Matthews and O.P.Strausz J.Chem.Phys.69 5105 (1978) ; M.Suto and L.C.Lee J.Chem.Phys.84 1160 (1986).

/10/ H.Okabe, Photochemistry of small molecules, Wiley, New York, NY, (1978) 